\title{
Critical Assessment of the Electric Effect in Electric Arc Welding
}

\author{
Rongshan Qin (1)
}

check for

updates

Citation: Qin, R. Critical Assessment of the Electric Effect in Electric Arc Welding. Metals 2021, 11, 1917. https://doi.org/10.3390/ met11121917

Academic Editor: Guillaume Racineux

Received: 18 October 2021

Accepted: 25 November 2021

Published: 27 November 2021

Publisher's Note: MDPI stays neutral with regard to jurisdictional claims in published maps and institutional affiliations.

Copyright: (C) 2021 by the author. Licensee MDPI, Basel, Switzerland. This article is an open access article distributed under the terms and conditions of the Creative Commons Attribution (CC BY) license (https:/ / creativecommons.org/licenses/by/ $4.0 /)$.
School of Engineering and Innovation, The Open University, Walton Hall, Milton Keynes MK7 6AA, UK; rongshan.qin@open.ac.uk

\begin{abstract}
This work provides a critical assessment of electric effects on the microstructure evolution at the heat-affected zone in electric arc welding. Electric effects are the interactions between electromagnetic fields and materials' microstructures. They differ from the arc effect and the Joule heating effect by providing an alternative contribution to nucleation, grain growth, recrystallisation and tempering. The influence of the electric effect on grain size, defects, anisotropic properties, precipitates and residual stress has been examined kinetically and thermodynamically. The use of adaptable electric current densities, pulse durations, pulse frequencies and electrode movements is suggested to achieve desirable microstructures and mechanical properties for the weldments.
\end{abstract}

Keywords: electric arc welding; electric effect; heat-affected zone; microstructure

\section{Introduction}

Electric arc welding (EAW) utilises an electric current between 100 and 1000 A to generate the electric arc. The arc heats up an electrode and joins metallic workpieces. EAW causes melting, solidification, recrystallisation and tempering [1]. The heat effect in EAW has been investigated over decades. The heat-affected zone (HAZ) represents the region where microstructures are altered. The microstructure in the HAZ is heterogeneous and different from the other areas. For example, the grain size in the grain-growth region is often larger than that in the recrystallisation region [2]. Despite significant research using modelling [3,4], experiments [5] and data-driven intelligent learning [6], there remains a further requirement to improve the quality of weldments. A more comprehensive scientific understanding is required toward minimising the detrimental effect of the HAZ in order to meet the progressive needs in the engineering practice.

The electric effect is different from the heat effect. The former is associated with an electromagnetic interaction and is described by Maxwell's equations. The latter is due to Joule heating and is governed by Ohm's law. Significant progress has been made in the understanding and the application of the electric effect in the electric current processing of materials [7]. The heat effect in electric current processing has been classified as a side effect, along with the skin effect, the pinch effect and electromigration [8]. To illustrate the significance of the electric effect in EAW, the current density implemented in spot welding has been calculated and compared with the observed electric effect in other electric-processing situations as follows: Most commercial EAW rods have a diameter between $1.6 \mathrm{~mm}$ and $4.0 \mathrm{~mm}$. With an operating current of $150 \mathrm{~A}$, the HAZ adjacent to the EAW rod with a $3.2 \mathrm{~mm}$ diameter bears an average current density of $1.86 \times 10^{7} \mathrm{~A} / \mathrm{m}^{2}$. This is significant because a current density around $1.0 \times 10^{3} \mathrm{~A} / \mathrm{m}^{2}$ has been found to increase the mobility of atoms and dislocations by a factor of one thousand [9], and a current density of $1.018 \times 10^{7} \mathrm{~A} / \mathrm{m}^{2}$ has been observed to be able to change the microstructure of low-carbon steels drastically at ambient condition [10]. In a liquid state, the critical value for the density of electric current to generate a considerable electric effect is much lower than the critical value in a solid state [11]. Despite the gradual reduction of the current density from the electrode across the HAZ to the matrix, due to the incrementation of the cross-section perpendicular to the current flow direction, the electric effects on liquid 
metal, grain growth, recrystallisation and tempering need to be assessed critically. The aim of this article was to conduct such an assessment in order to provide a comprehensive understanding of the mechanisms that affect the microstructures of weldments beyond the heat effect.

\section{The Electric Effects}

\subsection{Basic Consideration}

A schematic diagram of EAW is shown in Figure 1a. The power source provides either a direct current or an alternating current. The electrode can be either consumable or non-consumable. The electric arc is ionised air with high electrical conductivity, similar to that of the metals. The workpieces are mainly metallic materials, e.g., low-carbon steels. Figure $1 \mathrm{~b}$ illustrates a typical experimental setup for investigating the electric effect in materials processing. The major difference between Figure $1 a, b$ is the minimisation of Joule heating. This is achieved by minimising the contact resistance and replacing the continuous current with electric pulses. The required temperature in Figure $1 \mathrm{~b}$ is provided by a wellcontrolled furnace. The electric effect is considered based on the adiabatic assumption. The heat effect can add to the electric effect without interference. The temperature-dependent electrical properties have been counted in the consideration of the electric effect. The device shown in Figure $1 \mathrm{~b}$ can be considered as a model device for Figure 1a with the capability of investigating individual phenomena at various areas in the HAZ.

(a)

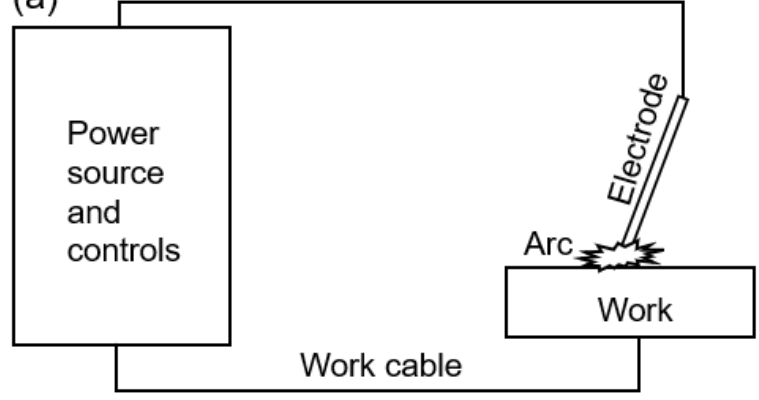

(b)

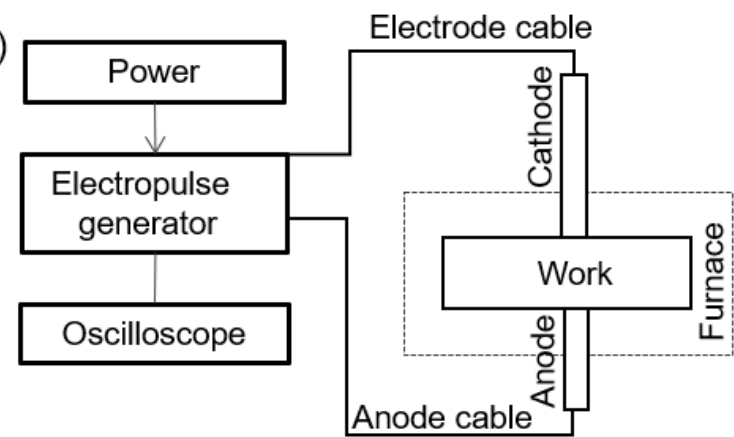

Figure 1. The schematic diagrams of (a) electric arc welding and (b) the electric effect investigation.

The electric effect affects both the kinetics and thermodynamics of materials' microstructural evolutions. Kinetically, a high electric current means the significant drifting of free electrons in the direction opposite the electric field. The drifting electrons are reflected unsymmetrically around each defect and cause a partial shielding effect in the repulsive force between the protons in adjacent atoms. This reduces the kinetic barrier for diffusion and enables a faster microstructural evolution in EAW than in other welding methods (e.g., laser welding). The kinetic effect of an electric current was initially identified in the material's electroplasticity [12], was subsequently validated by experimental characterisation $[13,14]$ and then applied to the deformation of brittle alloys such as magnesium alloys [15,16] and aluminium alloys [17] to improve their formability. The electric-current-induced acceleration in the microstructural evolution has also been observed in the precipitate dissolution [18] and the reversal of spinodal decomposition [19,20] in stainless steels. For example, microstructures formed over hundreds of hours without electric current have been observed to be dissolved within minutes by the electric current at the same temperature. This indicates that all of the processes in EAW can be expedited by the electric effect, and the contribution of the electric effect to the kinetics can be more significant than that from the heat effect.

Thermodynamically, electric current free energy is described by the Landau theory in the following format [21]:

$$
\mathrm{G}_{e}=-\frac{1}{2} \mu_{0} \mu_{i j} \mathrm{H}_{i} \mathrm{H}_{j}
$$


where $\mu$ is the magnetic permeability and $H_{i}$ is the $i$-th component of the magnetic field. Another format, obtained from an a priori derivation, according to Maxwell's equation, is [22]:

$$
\mathrm{G}_{e}=-\frac{1}{8 \pi} \iint \frac{\mu\left(v^{\prime}\right) \vec{J}\left(v^{\prime}\right) \cdot \vec{J}(v)}{\left|v-v^{\prime}\right|} d v d v^{\prime}
$$

where $\vec{J}(v)$ is the electric current density at a space position with an infinitesimal volume, $d v$. $v$ and $v^{\prime}$ represent two different positions within the material. Equation (2) shows that the electric current free energy is dependent on the spatial distribution of the current density. Any microstructural transformation can cause a change in the local electrical properties and, subsequently, a change in the local electric current density. For example, a grain-size refinement causes an increase in interface fraction. The electrical conductivity of the interface is different from that of the bulk crystals [23]. The grain refinement, therefore, causes the change in electric current free energy. In an inverse understanding, it can be said that the passing electric current affects the grain refinement. The change of electric current free energy, according to Equation (2), is dependent on the average current density square, the change in the electrical conductivities due to the microstructural evolution and the volume of materials. The detailed formats for the materials, at some specified geometries, have been calculated and are available in the literature [24,25].

The total free energy in the microstructure transformation consists of the chemical free energy, interface energy, strain-stress energy and electric current free energy [26]. The electric current free energy can change the system free energy differently than the heat effect. As discussed earlier in the present work, the kinetic effect of the electric current expedites the process and makes the material's microstructures evolve quickly along the new thermodynamic trend.

\subsection{Electric Effects on Grain Growth}

The electric current enhances the diffusivity drastically when the current density surpasses a critical value of $1.0 \times 10^{3} \mathrm{~A} / \mathrm{m}^{2}$ [9]. In diffusion-limited growth, the graingrowth rate is given by [27]:

$$
\vec{v}_{n}=-D \hat{n} \cdot \nabla c
$$

where $\hat{n}$ is a normal direction of a solid-liquid interface, $\vec{v}_{n}$ is the growth rate along $\hat{n}$ and $\nabla c$ is the gradient of the solute composition. Equation (3) shows that the electric current expedites the grain growth via an enhanced diffusivity. The higher grain-growth rate means a shorter nucleation time and, hence, a larger average grain size. A conventional consideration based on the heat effect in EAW suggests that coarse grains are formed because the molten materials are solidified in a low-temperature and high-thermal-conductive substrate. Equation (3) indicates an extra electric effect that contributes to the formation of a coarse-grained microstructure. It is well known that a high cooling rate causes the formation of brittle martensite in the medium- and high-carbon steel workpieces [28]. These steels are therefore classified as not weldable. If the diffusivity of carbon could be accelerated drastically by the electric effect and could surpass the quenching effect, the formation of brittle martensite would be avoidable because the carbon atoms could diffuse away from the body-centred-cubic phase to form carbides or to move to the residual face-centred-cubic austenite phase [29]. This means that the electric effect could, in principle, change the weldability of some engineering steels. Further investigations are required to assess its feasibility and to capitalise on this idea. The research could include the optimisation of the arc geometry and the electric current parameters to balance the diffusion and the rapid solidification.

From a thermodynamic point of view, the electric effect promotes microstructure evolution toward the state with the highest electrical conductivity [30]. It is well known that the crystalline phase has a higher electrical conductivity than the corresponding liquid and amorphous phases [31]. This indicates another growth that is due to the percolation 
effect of the electric current, as illustrated in Figure 2. The interface represented by the solid line (denoted as interface A) is encouraged by the electric effect more than the interface represented by the dashed line (denoted as interface B). Both cases have the same fraction of the solidified phase, but interface A has some grains grow faster than others and eventually form large anisotropic-shaped crystals. The case where some of the grains grow quickly toward the electrode causes the formation of several high-conductivity percolation paths and enables the electric current free energy to be lower than that of the case illustrated in interface B. The percolation-caused growth is detrimental to the quality of the weldment because those large grains can form an interconnected frame to reduce the fluidity of the unsolidified metal. The latter causes the formation of defects, pores, residual stress and hot cracks [32] because the volume shrink during cooling in the isolated areas is unable to be refilled by other liquid metals. For a similar thermodynamic reason, aligned growth can take place in electric processing $[33,34]$. This is because the different phases have different electrical conductivities. An aligned microstructure promotes percolation and maximises the material's effective electrical conductivity along certain orientations. The electric effect can also cause the anisotropic objects to rotate in the liquid phase. Numerical calculations have shown that the needles [35] and thin flakes [36] of the low-electrical-conductivity phases in a high-conductive liquid can rotate and eventually align to the direction of the electric field.

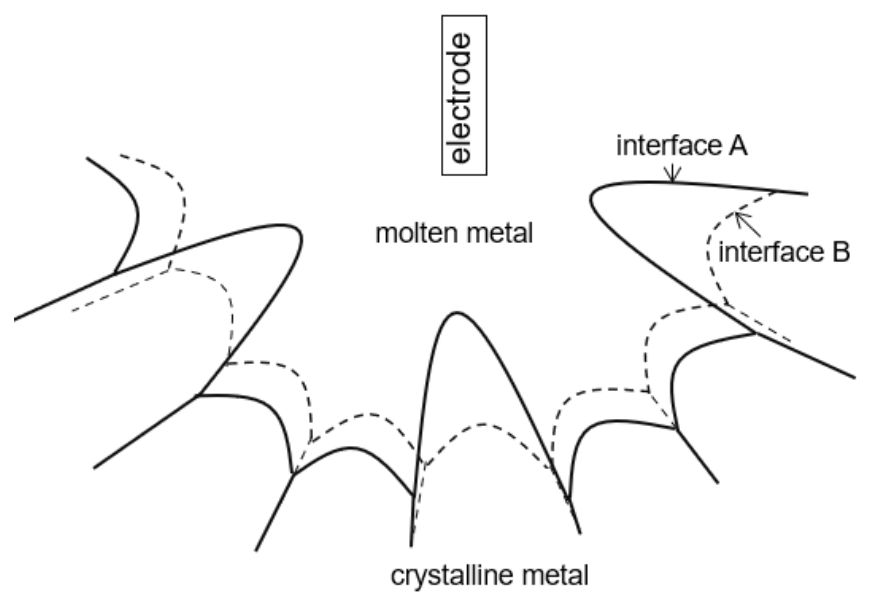

Figure 2. The schematic diagram shows the grain growth under the electric effect (interface A) and under the heat effect (interface B).

In addition to the previously discussed positive and negative electric effects on grain growth during the quenching of molten materials in a welding pool, the electric effect has a significant influence on nucleation. Experimental observations have reported the current-promoted nucleation rate in the solidification of metallic materials $[8,11,37,38]$. A nucleation theory based on electric current free energy has been developed [39]. Electric current makes the free-energy density difference between the supercooled liquid and the crystalline phase more severe. This reduces the critical radius of nuclei in solidification. A numerical calculation shows a good agreement between the theoretical prediction and the experimental characterisation. It is also assumed that the electric field modifies the solid-liquid interface energy [8], despite this not having been validated experimentally. The enhanced nucleation rate is favourable to the grain refinement in casting. In the early stage of crystal growth, the electrical conductivity of the nanoscale crystalline is often anomalous [40] and can sometimes cause the suspension effect to prolong the nucleation time [41]. The overall contribution from the electric effects on the final grain size in the HAZ is decided by the competition between various factors. This is, however, controllable and can be adjusted to achieve the favourable microstructure and prevent the undesirable microstructure from developing. 


\subsection{Electric Effect on Recrystallisation}

Recrystallisation is a microstructural relaxation driven by the second law of thermodynamics in a minimisation of the system's free energy without a phase transition [42]. It is often achievable by the minimisation of the interface energy and the mitigation of residual stress. An example is the spheroidisation of lamellar grains [43]. The total interface energy is reduced via the microstructural evolution. The heat effect is known to improve the diffusivity and expedite the recrystallisation. The residual strain-stress energy also provides a thermodynamic driving force for recrystallisation. The electric effect provides not only higher mobility to enable quicker recrystallisation but also an extra electric current free energy to enable the finer than conventionally expected microstructure to form. The mechanism behind this is indicated in the following equation:

$$
S_{\text {bef }} \geq S_{\text {aft }}+\left(\Delta G_{e}+\Delta G_{s}\right) / \sigma
$$

where $S_{b e f}$ and $S_{a f t}$ are the interface areas before and after recrystallisation, respectively. $\Delta G_{e}$ and $\Delta G_{s}$ are the electric current free energy difference and stress-strain energy difference in the recrystallisation, respectively. $\sigma$ is the interface tension. In the case when $\Delta G_{e}+\Delta G_{s}=0$, the total interface area after the spheroidisation should be less than the area before recrystallisation. For any given morphology of elongated grain, Equation (4) can be used to calculate the minimum average grain size after recrystallisation. When the electric current free energy satisfies $\Delta G_{e}<0$, it is unnecessary to have $S_{b e f} \geq S_{\text {aft }}$ because the negative value of $\Delta G_{e}$ can be used to compensate for the extra interface energy in the grain refinement. This means that the minimum grain size from a traditional theoretical prediction can be exceeded [44]. The finer microstructures have been observed experimentally [45]. The negative electric current free energy is obtainable when the electrical conductance of the materials increases after the recrystallisation.

To illustrate this straightforwardly, a numerical calculation for the current density distribution was performed and the electric current free energy was calculated according to Equation (2). These results are shown for the first time, as follows. The numerical data were plotted using MatVisual software. The electric current density was obtained by first calculating the static electric potential distribution and then using Ohm's law to calculate the electric current. The static electric potential distribution was calculated by a relaxation method and Kirchhoff's law. The virtual system was subjected to an electric potential difference of $20 \mathrm{~V}$ in a horizontal direction. The electrical potential in the left end was higher than that in the right end. The material contained two phases. The matrix had a higher electrical conductivity than that of the embedded phase. For a realistic calculation, the physical parameters of ferrite (electrical conductivity at $9.17 \times 10^{6} \mathrm{~S} \cdot \mathrm{m}^{-1}$ and magnetic permeability $300 \mu_{0}$ ) were used for the matrix, and the physical parameters of cementite (electrical conductivity at $1.22 \times 10^{6} \mathrm{~S} \cdot \mathrm{m}^{-1}$ and magnetic permeability $30 \mu_{0}$ ) were used for the embedded phase. The calculation was performed on a lattice containing $201 \times 91 \times 81$ number of cubic grids. The electric current distribution is shown in Figure 3. The grains at flat shapes shown in Figure 3a are broken and spheroidised in Figure 3b. The numerical calculation shows that the electric current free energy in Figure $3 \mathrm{~b}$ is much lower than that in Figure $3 \mathrm{a}$. The electric effect has promoted the formation of a finer microstructure. 

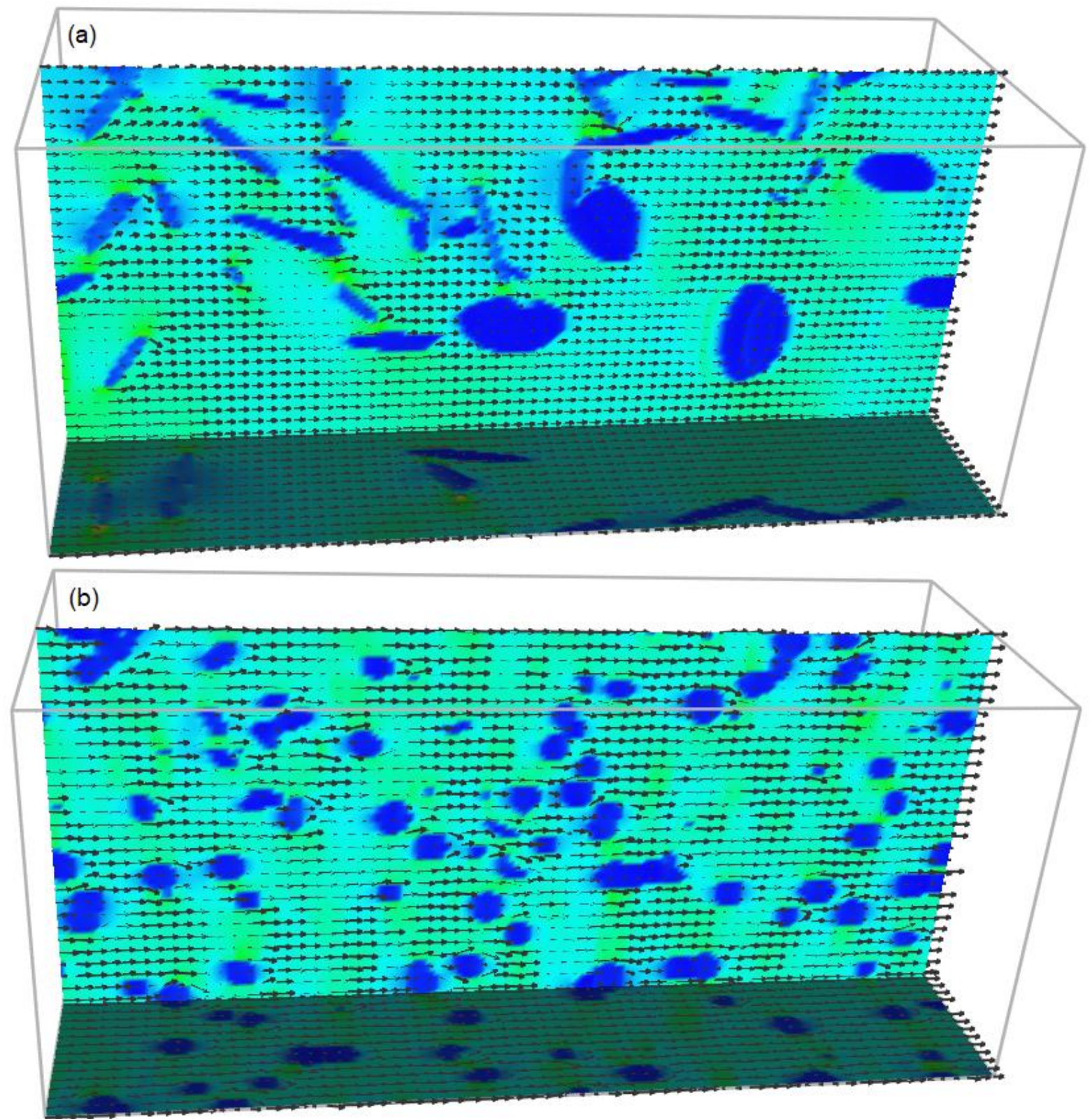

Figure 3. The electric current distributions in a high-conductive matrix containing low-conductive (a) plate shapes and (b) broken and spheroidised grains.

For the materials containing residual stress, the recrystallisation-induced residualstress mitigation means a negative value of strain-stress energy $\left(\Delta G_{S}<0\right)$. The release of the residual strain-stress energy can contribute to the microstructure evolution in recrystallisation and makes the grains even finer. The residual stress is often formed during the phase transition, quenching and mechanical deformation. The combination of the electric effect and the residual stress effect has been implemented to fabricate nanostructured steels $[45,46]$. Electric current pulses were applied at around $10^{9} \mathrm{~A} / \mathrm{m}^{2}$ to a cold-drawn high-carbon pearlitic-steel wire (Fe-0.8C-0.2Si-0.5Mn wt.\%) to $60 \%$ elongation and obtained very fine cementite particles. Figure 4 shows a scanning electron microscope (SEM) image after recrystallisation of this wire. The figure is shown for the first time in the present work. Spheroidized nanoscale $\mathrm{FeC}_{3}$ particles are seen throughout the image, while the original microstructure before recrystallisation was a deformed lamellar pearlite. It is not possible to form such fine grains by rearrangement of the interface energy alone. The electric effect and residual stress have both played their roles. 


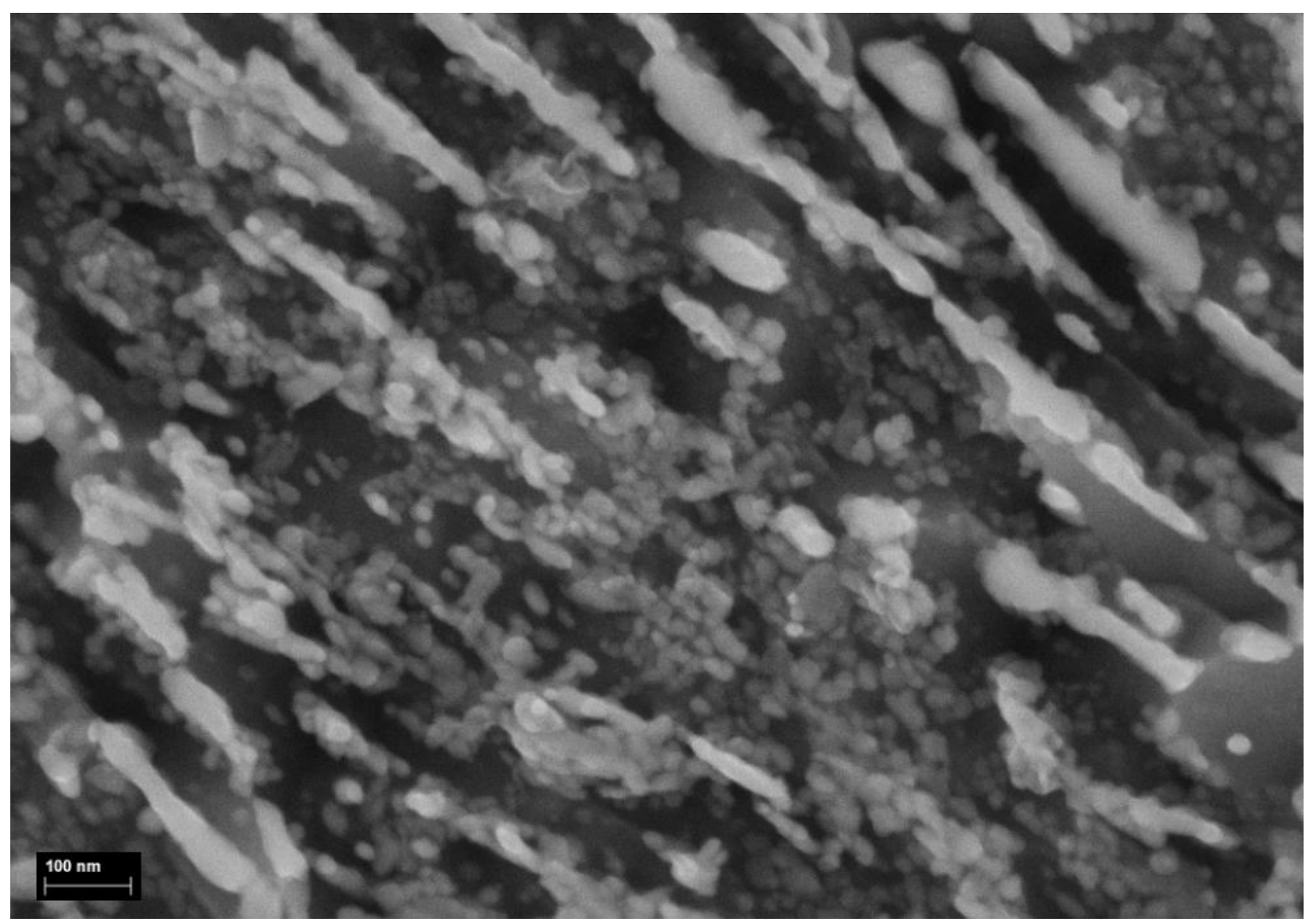

Figure 4. Electric-effect-induced formation of nanostructured $\mathrm{FeC}_{3}$ grains from the originally thin plate in cold-drawn pearlitic wire.

The electric effect has the potential to cause an anisotropic microstructure to form. Klinger and Levin analysed the interface instability in an electric field and reported that the interface migration rate was enhanced along the direction parallel to the electric field [47]. A similar phenomenon was revealed in the calculation of the agglomeration of inclusions in liquid steel at the electric field [48]. This has also been noticed in the cementite spheroidisation experiments described earlier in the work. In some cases, when the electric current density is insufficiently high, the cementite plates perpendicular to the electric field direction are broken into small pieces, but some other plates parallel to the electric field are less fractured, as is shown in the SEM image in Figure 5. A higher electric current density is required to break all of the lamellar structures into smaller particles, if not to consider the change of electric current direction by rotating the samples or electrodes.

\subsection{Electric Effect on Tempering}

Tempering is a heat treatment to improve a material's mechanical properties, such as fracture toughness and the distribution of residual stress. The influence of the electric current on the diffusivity and the free energy allows the electric current to accelerate the structural relaxation. Experiments have shown the electric effects on the hardness, tensile property, residual stresses, microstructures and dislocation density of quenched mediumcarbon steels [49] and the martensite phase in dual-phase steels [50]. The wear resistance and the corrosion behaviour in deep cryogenically treated steels have been modified due to the accelerated diffusivity of the carbon in the formation and the configuration of carbides [51]. The electric effect on precipitation has been reported in various alloys [52,53]. 


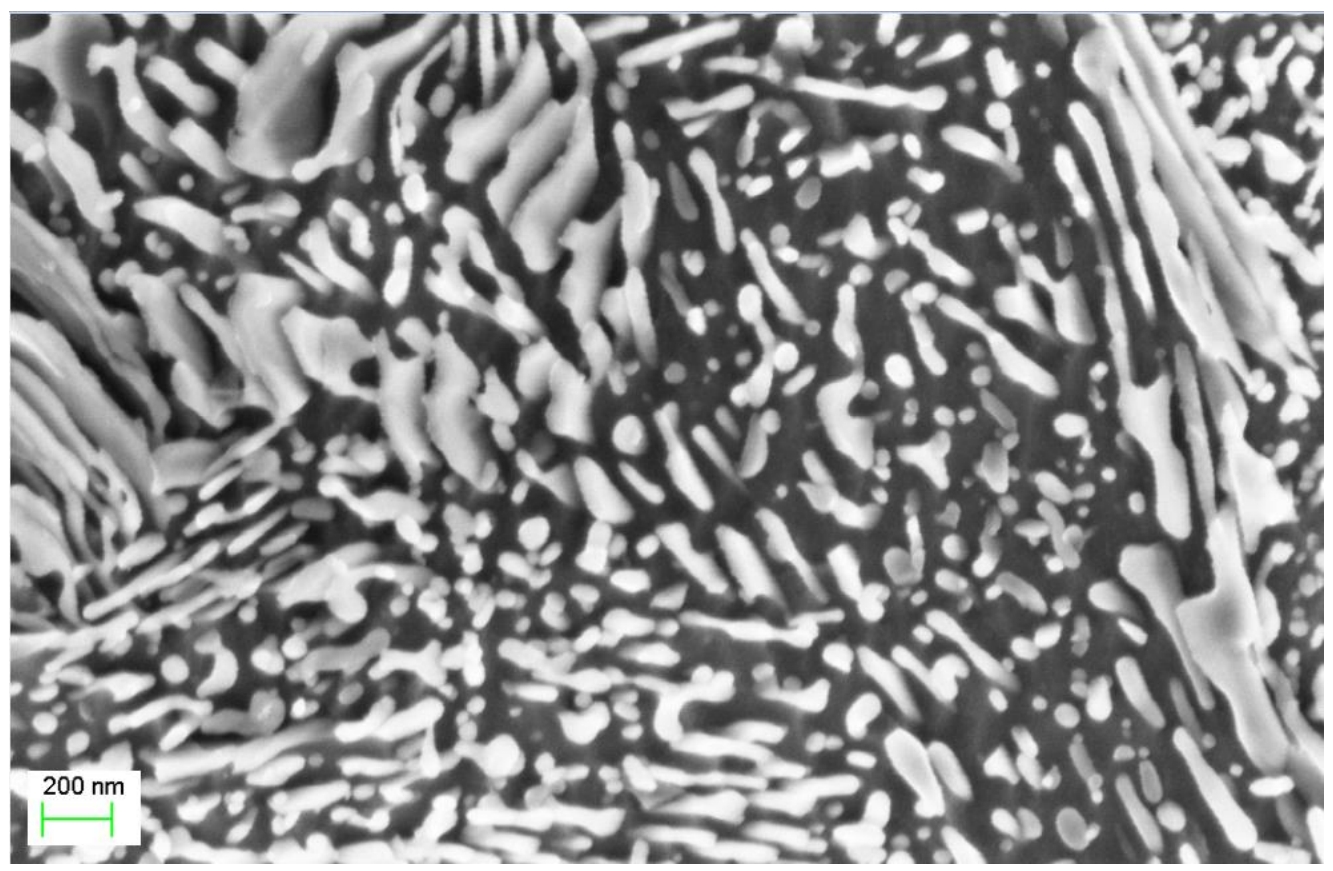

Figure 5. An SEM image shows the anisotropic fracture of the cementite plates in electropulseinduced recrystallisation of pearlite steels.

An electric current treatment can alternate the residual stress in metallic materials $[54,55]$. This is often related to dislocation annihilation [56] and structural relaxation. Presently, it has not been established that an electric current can remove residual stress without causing notable microstructural alternation. However, converting tensile stress to compressive stress is easily achieved using electric current processing $[57,58]$. Although the mechanism behind this phenomenon can be linked to the pinch effect of the electric current, it is more likely that the relationship between the electrical conductivity and the hydrostatic pressure plays a role. Most metallic materials have a higher electrical conductivity under a higher pressure [59]. The electric current free energy is lower in the high-conductivity state than in the low-conductivity state, according to the earlier discussions in this work. The electric effect, therefore, drives the materials to evolve toward the highest conductive state in order to minimise the electric current free energy. This generates compressive residual stress.

\section{Optimising the Electric Effect in EAW}

To balance the heat effect and the electric effect in EAW in order to achieve a desirable microstructure and the ideal mechanical properties in weldments, electric current parameters should be designed to be able to optimise all of the electric effects that have been discussed earlier in this article. Pulsed electric current should replace the continuous current. There are already many successful examples of this transition $[60,61]$. The electric parameters include the electric current density, pulse duration, pulse frequency, electrode movement and loading time. The shape and the size of the arc should be designed to fit the need for welding at the various electric parameters.

For the electric effect in grain growth, electric current promotes both nucleation and grain growth. The finer microstructure can be achieved by a higher nucleation rate and a lower growth rate. The nucleation rate is proportional to the exponential current density square. It should, therefore, apply a high-density short-duration electric current to the molten materials in the nucleation stage. In the growth stage, the current density should be reduced to less than the critical value so that the diffusivity is not enhanced by the current. The ideal temperature for nucleation is different from that for growth. There is a possibility to adjust this to achieve a desirable situation. 
The electric current free energy affects the phase stability sequence in the weldments. This can be used to control the formation and the morphology of the phases and the precipitates [62]. The effect of the electric current on the precipitations has been reported to be either an acceleration [52] or a retardation [63,64]. Both cases should have identical thermodynamic reasons, and the differences should come from the electrical and magnetic properties of the precipitates and the matrix. The electric current free energy should be included in the prediction and the calculation of the phase diagram in EAW, which is possible due to the significant progress in computational thermodynamics and phase diagrams [26].

The location of the electrode should be changed during the welding process to avoid the formation of an anisotropic microstructure and texture in the HAZ. This can be rather complicated due to the accompanied movement of the arc and the temperature profile. Computation of the electric current effect [22] should be integrated with the computation of the heat and mass transfer to optimise the EAW processing.

\section{Conclusions}

Through the critical assessment of the electric effects on the heat-affected zone in electric arc welding, the following points have been drawn.

The electric effect influences the nucleation rate and the grain-growth rate in the solidification of metals and alloys in the HAZ. The nucleation is mainly affected by the electric current free energy, which is dependent on the electrical properties of the crystalline and liquid metals, the microstructure and the electric current density. The grain-growth rate is mainly affected by the current-enhanced diffusivity. An elegant design of the adaptive electric current parameters can lead to a desirable microstructure in the HAZ.

The electric effect plays an important role in recrystallisation. Experiments have shown the significant refinement of materials' microstructures by the electric effect. Precautions to be considered include the potential formation of an anisotropic structure that leads to undesirable anisotropic mechanical properties. Design for the movement of electrodes has the potential to minimise the anisotropic effect.

The electric effect is suitable for tempering treatment of the material's microstructure and properties. The current-enhanced mobility of atoms and dislocations promotes structural relaxation. Current-induced residual-stress redistribution can generate favourable material properties in weldments.

It is possible to improve the weldability of some materials using the electric current enhanced diffusivity.

Funding: The work has been funded by the European Commission's Research Fund for Coal and Steel under Grant Agreement No 847269 and from the Engineering and Physical Sciences Research Council in the UK under Grant Agreement No EP/R029598/1.

Institutional Review Board Statement: Not applicable.

Informed Consent Statement: Not applicable.

Data Availability Statement: Data is contained within the article.

Acknowledgments: The author is grateful for the current and previous collaborators who worked on this topic, including E.I. Samuel, A. Bhowmik, A. Rahnama, X.F. Zhang, W.J. Lu, Y.K. Luo, S. Adande, O. Omoigiade, Z.C. Zhao and others. Figure 3 was plotted using MatVisual software.

Conflicts of Interest: The author declares no conflict of interest.

\section{References}

1. Amanie, J. Effect of Submerged Arc Welding Parameters on the Microstructure of SA516 and A709 Steel Welds. Ph.D. Thesis, University of Saskatchewan, Saskatoon, SK, Canada, 2011.

2. Lee, C.S.; Chandel, R.S.; Seow, H.P. Effect of welding parameters on the size of heat affected zone of submerged arc welding. Mater. Manuf. Process. 2000, 15, 649-666. [CrossRef]

3. Ducharme, R.; Kapadia, P.; Dowden, J.; Thornton, M.; Richardson, I. A mathematical-model of the arc in electric-arc welding including shielding gas-flow and cathode spot location. J. Phys. D Appl. Phys. 1995, 28, 1840-1850. [CrossRef] 
4. Varbai, B.; Májlinger, K. Physical and theoretical modeling of the nitrogen content of duplex stainless steel weld metal: Shielding gas composition and heat input effects. Metals 2019, 9, 762. [CrossRef]

5. Suleimanov, R.I.; Zainagalina, L.Z.; Khabibullin, M.Y.; Zaripova, L.M.; Kovalev, N.O. Studying heat-affected zone deformations of electric arc welding. IOP Conf. Ser. Mater. Sci. Eng. 2018, 327, 032053. [CrossRef]

6. Nogay, H.S.; Akinci, T.C. Classification of operation cases in electric arc welding wachine by using deep convolutional neural networks. Neural. Comput. Appl. 2021, 33, 6657-6670. [CrossRef]

7. Dolinsky, Y.; Elperin, T. Thermodynamics of nucleation in current-carrying conductors. Phys. Rev. B 1994, 50, 52-58. [CrossRef] [PubMed]

8. Barnak, J.P.; Sprecher, A.F.; Conrad, H. Colony (grain) size reduction in eutectic Pb-Sn castings by electropulsing. Scr. Metall. Mater. 1995, 32, 879-884. [CrossRef]

9. Conrad, $\mathrm{H}$. Influence of an electric or magnetic field on the liquid-solid transformation in materials and on the microstructure of the solid. Mater. Sci. Eng. A 2000, 287, 205-212. [CrossRef]

10. Rahnama, A.; Qin, R.S. Electropulse-induced microstructural evolution in a ferritic-pearlitic $0.14 \%$ C steel. Scr. Mater. 2015, 96, 17-20. [CrossRef]

11. Misra, A.K. A novel solidification technique of metals and alloys-Under the influence of applied potential. Metall. Trans. A 1985, 16, 1354-1355. [CrossRef]

12. Troitskii, O.A. Electromechanical effect in metals. JETP Lett. 1969, 10, 11-14. (English version)

13. Zhao, S.T.; Zhang, R.P.; Chong, Y.; Li, X.Q.; Abu-Odeh, A.; Rothchild, E.; Chrzan, D.C.; Asta, M.; Morris, J.W., Jr.; Minor, A.M. Defect reconfiguration in a Ti-Al alloy via electroplasticity. Nat. Mate. 2021, 20, 468-472. [CrossRef]

14. Kim, M.J.; Yoon, S.M.; Park, S.W.; Jeong, H.J.; Park, J.W.; Kim, K.T.; Jo, J.H.; Heo, T.H.; Hong, S.T.; Cho, S.H.; et al. Elucidating the origin of electroplasticity in metallic materials. Appl. Mater. Today. 2020, 21, 100874. [CrossRef]

15. Jiang, B.; Zhang, D.D.; Xu, H.; Liu, Y.B.; Cao, Z.Y.; Yang, X.H. Excellent ductility in the extruded AZ61 magnesium alloy tube induced by electropulsing treatment during tension. Metals 2021, 11, 813. [CrossRef]

16. Jiang, Y.B.; Tang, G.Y.; Shek, C.H.; Zhu, Y.H.; Xu, Z.H. On the thermodynamics and kinetics of electropulsing induced dissolution of $\beta-\mathrm{Mg}_{17} \mathrm{Al}_{12}$ phase in an aged Mg-9Al-1Zn alloy. Acta Mater. 2009, 57, 4797-4808. [CrossRef]

17. Kim, M.J.; Lee, K.; Oh, K.H.; Choi, I.-S.; Yu, H.-H.; Hong, S.-T.; Han, H.N. Electric current-induced annealing during uniaxial tension of aluminum alloy. Scripta Mater. 2014, 75, 58-61. [CrossRef]

18. Lu, W.J.; Zhang, X.F.; Qin, R.S. Stability of precipitates under electropulsing in 316 L stainless steel. Mater. Sci. Technol. 2015, 31, 1530-1535. [CrossRef]

19. Zhao, Y.; He, B.Y.; Saillet, S.; Domain, D.; Delliou, P.L.; Perez, M.; Qin, R.S. Anti-aging treatment of nuclear power plant steel. Mater. Sci. Eng. A 2018, 735, 73-80. [CrossRef]

20. Liu, X.B.; Lu, W.J.; Zhang, X.F. Reconstructing the decomposed ferrite phase to achieve toughness regeneration in a duplex stainless steel. Acta Mater. 2020, 183, 51-63. [CrossRef]

21. Eerenstein, W.; Mathur, N.D.; Scott, J.F. Multiferroic and magnetoelectric materials. Nature 2006, 442, 759-765. [CrossRef] [PubMed]

22. Qin, R.S.; Bhowmik, A. Computational thermodynamics in electric current metallurgy. Mater. Sci. Technol. 2015, 31, 1560-1563. [CrossRef]

23. Mohanty, U.; Rice, S.A. Theory of the electrical conductivity in the liquid vapor interface of a simple metal. J. Chem. Phys. 1983, 79, 5652-5657. [CrossRef]

24. Zhang, X.F.; Qin, R.S. Electric current-driven migration of electrically neutral particles in liquids. Appl. Phys. Lett. 2014, 104, 114106. [CrossRef]

25. Qin, R.S.; Su, S.X. Thermodynamics of crack healing under electropulsing. J. Mater. Res. 2002, 17, 2048-2052. [CrossRef]

26. Liu, Z.K. Computational thermodynamics and its applications. Acta Mater. 2020, 200, 745-792. [CrossRef]

27. Langer, J.S.; Müller-Krumbhaar, H. Theory of dendritic growth-I. Elements of a stability analysis. Acta Metall. 1978, 26, 1681-1687. [CrossRef]

28. Bhadeshia, H.K.D.H. Problems in the welding of automotive alloys. Sci. Technol. Weld. Join. 2015, 20, 451-453. [CrossRef]

29. Jung, G.S.; Lee, K.Y.; Lee, J.B.; Bhadeshia, H.K.D.H.; Suh, D.W. Spot weldability of TRIP assisted steels with high carbon and aluminium contents. Sci. Technol. Weld. Join. 2012, 17, 92-98. [CrossRef]

30. Qin, R.S.; Rahnama, A.; Lu, W.J.; Zhang, X.F.; Elliott-Bowman, B. Electropulsed steels. Mater. Sci. Technol. 2014, 30, 1040-1044. [CrossRef]

31. Powell, R.W. LXXX. The electrical resistivity of liquid iron. Phil. Mag. 1953, 44, 772-775. [CrossRef]

32. Kannengiesser, T.; Boellinghaus, T. Hot cracking tests-an overview of present technologies and applications. Weld. World 2014, 58, 397-421. [CrossRef]

33. Yousefi, N.; Gudarzi, M.M.; Zheng, Q.B.; Aboutalebi, S.H.; Sharif, F.; Kim, J.K. Self-alignment and high electrical conductivity of ultra large graphene oxide-polyurethane nanocomposites. J. Mater. Chem. 2012, 22, 12709-12717. [CrossRef]

34. Yamauchi, K.; Hagio, T.; Mitsuo, T.; Iwai, K.; Itoh, T. Thermoelectric properties of crystal aligned higher manganese silicide fabricated by solidification under magnetic field. Jpn. J. Appl. Phys. 2015, 54, 117102. [CrossRef]

35. Qin, R. Alignment of rods and flakes using electric field. Adv. Mater. Lett. 2019, 10, 899-902. [CrossRef] 
36. Qin, R. Electric-field-induced alignment of electrically neutral disk-like particles: Modelling and calculation. Sci. Rep. 2017, 7, 8449. [CrossRef] [PubMed]

37. Jiang, H.X.; Zhao, J.Z.; Wang, C.P.; Liu, X.J. Effect of electric current pulses on solidification of immiscible alloys. Mater. Lett. 2014, 132, 66-69. [CrossRef]

38. Jiang, H.X.; He, J.; Zhao, J.Z. Influence of electric current pulses on the solidification of Cu-Bi-Sn immiscible alloys. Sci. Rep. 2015, 5,12680 .

39. Qin, R.S.; Zhou, B.L. Effect of electric current pulses on grain size in castings. Inter. J. Nonequil. Proc. 1998, 11, 77-86.

40. Liu, S.H.; Poirier, D.R.; Ocansey, P.N. Resistivity of $\mathrm{Pb}$ and $\mathrm{Pb}-10 \mathrm{wt} \% \mathrm{Sn}$ during solidification. Metall. Mater. Trans. 1995, 26A, 741-745. [CrossRef]

41. Qin, R.S.; Su, S.X.; Guo, J.D.; He, G.H.; Zhou, B.L. Suspension effect of nanocrystalline grain growth under electropulsing. Nanostruc. Mater. 1998, 10, 71-76.

42. Huang, K.; Loge, R.E. A review of dynamic recrystallization phenomena in metallic materials. Mater. Des. 2016, 111, 548-574. [CrossRef]

43. Samuel, E.I.; Bhowmik, A.; Qin, R.S. Accelerated spheroidization induced by high intensity electric pulse in a severely deformed eutectoid steel. J. Mater. Res. 2010, 25, 1020-1024. [CrossRef]

44. Qin, R. Using electric current to surpass the microstructure breakup limit. Sci. Rep. 2017, 7, 41451. [CrossRef]

45. Qin, R.S.; Samuel, E.I.; Bhowmik, A. Electropulse-induced cementite nanoparticle formation in deformed pearlitic steels. J. Mater. Sci. 2011, 46, 2838-2842. [CrossRef]

46. Qin, R.S.; Luo, Y.K.; Elliott-Bowman, B.; Omoigiade, O. Fabrication of nanostructured pearlite steel wires using electropulsing. Mater. Sci. Technol. 2018, 34, 29-34. [CrossRef]

47. Klinger, L.; Levin, L. Interface instability in an electric-field. J. App. Phys. 1995, 78, 1669-1672. [CrossRef]

48. Zhao, Z.C.; Qin, R.S. Morphology and orientation selection of non-metallic inclusions in electrified molten metal. Metall. Mater. Trans. 2017, 48B, 2781-2787. [CrossRef]

49. Pan, L.; He, W.; Gu, B.P. Effects of electric current pulses on mechanical properties and microstructures of as-quenched medium carbon steel. Mater. Sci. Eng. A 2016, 662, 404-411. [CrossRef]

50. Lu, W.J.; Qin, R.S. Stability of martensite with pulsed electric current in dual-phase steels. Mater. Sci. Eng. A 2016, 677, 252-258. [CrossRef]

51. Amini, K.; Akhbarizadeh, A.; Javadpour, S. Effect of carbide distribution on corrosion behavior of the deep cryogenically treated 1.2080 steel. J. Mater. Eng. Perform. 2016, 25, 365-373. [CrossRef]

52. Kapoor, R.; Sunil, S.; Reddy, G.B.; Nagaraju, S.; Kolge, T.S.; Sarkar, S.K.; Biswas, A.; Sharma, A. Electric current induced precipitation in maraging steel. Scr. Mater. 2018, 154, 16-19. [CrossRef]

53. Lu, W.J.; Qin, R.S. Influence of K-carbide interface structure on the formability of lightweight steels. Mater. Des. 2016, 104, 211-216. [CrossRef]

54. Sydorenko, Y.M.; Pashchyn, M.O.; Mykhodui, O.L.; Khokhlova, Y.A.; Khokhlov, M.A. Effect of pulse current on residual stresses in AMg6 aluminum alloy in electrodynamic treatment. Strength Mater. 2020, 5, 731-737. [CrossRef]

55. Xiang, S.Q.; Zhang, X.F. Residual stress removal under pulsed electric current. Acta Metall. Sin.-Engl. 2020, 33, 281-289. [CrossRef]

56. Song, X.D.; Wang, F.; Qian, D.S.; Hua, L. Tailoring the residual stress and mechanical properties by electroshocking treatment in cold rolled M50 steel. Mater. Sci. Eng. A 2020, 780, 139171. [CrossRef]

57. Ye, Y.D.; Kure-Chu, S.Z.; Sun, Z.Y.; Li, X.P.; Wang, H.B.; Tang, G.Y. Nanocrystallization and enhanced surface mechanical properties of commercial pure titanium by electropulsing-assisted ultrasonic surface rolling. Mater. Des. 2018, 149, $214-227$. [CrossRef]

58. Omoigiade, O. Microstructure and Properties of Electropulsed High Carbon Steel Wire Rod. Ph.D. Thesis, Imperial College London, London, UK, 2018.

59. Lawson, A.W. The effect of hydrostatic pressure on the electrical resistivity of metals. Prog. Phys. Met. 1956, 6, 1-44. [CrossRef]

60. Palani, P.K.; Murugan, N. Selection of parameters of pulsed current gas metal arc welding. J. Mater. Proc. Technol. 2006, 172, 1-10. [CrossRef]

61. Yang, M.X.; Bai, R.R.; Zheng, H.; Qi, B.J. Temperature monitoring and calibration in Ti-6Al-4V molten pool with pulsed arc welding. Sci. Technol. Weld. Join. 2020, 25, 369-376. [CrossRef]

62. Ram, G.D.J.; Reddy, A.V.; Rao, K.P.; Reddy, G.M. Control of Laves phase in Inconel 718 GTA welds with current pulsing. Sci. Technol. Weld. Join. 2004, 9, 390-398.

63. Onodera, Y.; Hirano, K.I. The effect of direct electric current on precipitation in a bulk Al-4 wt\% Cu alloy. J. Mater. Sci. 1976, 11, 809-816. [CrossRef]

64. Onodera, Y.; Maruyama, J.I.; Hirano, K.I. Retardation of the precipitation reaction by d.c. stress in an Al- $12.5 \mathrm{wt} \% \mathrm{Zn}$ alloy. J. Mater. Sci. 1977, 12, 1109-1114. [CrossRef] 